\title{
Expression and regulation of fucosyltransferase 4 in human endometrium
}

\author{
Anna P Ponnampalam and Peter A W Rogers \\ Monash University Department of Obstetrics and Gynaecology and Monash Institute of Medical Research, Centre for \\ Women's Health Research, Monash Medical Centre, Clayton, Victoria 3168, Australia \\ Correspondence should be addressed to A P Ponnampalam who is now at Liggins Institute, The University of Auckland, Auckland, \\ New Zealand; Email: a.ponnampalam@auckland.ac.nz
}

\begin{abstract}
It has been suggested that selectin ligands expressed by the endometrial epithelium are essential for the initial adhesion of the blastocyst to the luminal epithelium of human endometrium. One of the enzymes responsible for the production of selectin ligands is fucosyltransferase 4 (FUT4), a member of $\alpha 1,3$ fucosyltransferases. The aims of the present study were to characterize FUT4 mRNA and protein in human endometrium during the menstrual cycle and to investigate the hormonal regulation of FUT4 whose mRNA expression was quantified by real-time PCR in fresh endometrial tissue from cycling women and protein expression was analyzed by immunohistochemistry and Western blotting. Hormonal regulation of FUT4 transcription was investigated using an endometrial explant system. FUT4 mRNA was significantly upregulated in fresh tissues during early and mid-secretory phases when compared with other phases of the menstrual cycle. FUT4 protein was localized to glandular and luminal epithelium and the expression levels followed the same pattern as for FUT4 mRNA. Our data also show that, in proliferative explants, progesterone significantly increased FUT4 transcription and translation after $24 \mathrm{~h}$ in culture. The inductive effect of progesterone on FUT4 transcription was lost after $48 \mathrm{~h}$ of treatment. Estrogen did not have any significant effects. These data suggest that the upregulation of selectin ligands in the human endometrium at the time of implantation may be mediated, at least in part, by the regulation of FUT4 expression.

Reproduction (2008) 136 117-123
\end{abstract}

\section{Introduction}

Endometrium goes through a complex series of cyclic changes each month, under the influence of fluctuating levels of the ovarian steroids, estrogen and progesterone, in preparation for implantation. In the absence of pregnancy, the fall in serum levels of steroids results in the shedding of the functionalis layer of the endometrium. Uncovering the molecular basis of these complex changes is fundamental to understanding the mechanisms that direct the biological processes associated with the endometrium such as proliferation, embryo implantation, and menstruation. We have previously investigated the changing transcriptional profile of the human endometrium during the menstrual cycle to better understand the molecular complexities of endometrial biology (Ponnampalam et al. 2004). Data from this study showed that one of the genes that altered expression significantly during the menstrual cycle was fucosyltransferase 4 (FUT4).

FUT4 is a member of a family of glycosyltransferases called fucosyltransferases. The fucosyltransferase gene family encodes enzymes that transfer fucose in $\alpha 1,2$, $\alpha 1,3 / 4$, and $\alpha 1,6$ linkages on a large variety of glycans (Huang et al. 2000, Wagers \& Kansas 2000, Withers
\& Hakomori 2000, de Vries et al. 2001). FUT4 belongs to a subfamily of $\alpha 1 \rightarrow 3 / 4$ fucosyltransferases. Glycosylation is one of the main post-translational modifications that have been shown to be important for the function of numerous glycoproteins. In mammals, fucosylated glycans linked to proteins are involved in a wide range of mechanisms such as cell adhesion during development (Clarke \& Watkins 1996, Wiederschain et al. 1998), inflammatory response, and leukocyte trafficking (Lowe 1997, Blander et al. 1999, Huang et al. 2000). Fucosyltransferases play a crucial role in the production of $\mathrm{ABO}$ blood group antigens and Lewis systems (Mollicone et al. 1995).

Our array and real-time PCR data show that FUT4 mRNA is upregulated during early and mid-secretory phases of the menstrual cycle (Ponnampalam et al. 2004). The aims of the current study were to further investigate cyclic changes of FUT4 mRNA in human endometrium during the menstrual cycle, to localize protein expression, and to examine the hormonal regulation of FUT4 mRNA and protein expression. Based on the array results, we hypothesized that FUT4 expression is regulated by progesterone in human endometrium. 


\section{Results}

\section{FUT4 mRNA expression and protein localization during the menstrual cycle}

Temporal expression of FUT4 mRNA during the menstrual cycle is shown in Fig. 1. FUT4 mRNA is significantly upregulated during the early and midsecretory stages of the menstrual cycle compared with the other menstrual phases, with maximal expression during the mid-secretory phase. These results confirm and extend previous observations (Ponnampalam et al. 2004) by significantly increasing the sample number and utilizing a histopathological rather than molecular classification of the menstrual cycle.

\section{FUT4 protein localization in the human endometrium}

Immunostaining for FUT4 was seen throughout the menstrual cycle in glandular and luminal epithelium. The intensity of the staining was weak in proliferative and menstrual endometrium and was strong during early and mid-secretory phases of the menstrual cycle. Replacing the FUT4 antibody with an equivalent amount of control goat IgG resulted in the complete absence of immunoreactivity (Fig. 2).

\section{Steroid hormone regulation of FUT4 transcription after 24 and $48 h$}

There was a significant difference between 24-h treatment groups for proliferative and secretory explants $(P=0.0033$ and $P=0.0062$ respectively, Friedman test). Individual group comparisons showed that FUT4 transcription was significantly increased in proliferative explants treated with progesterone. Although there was a trend toward an increase in FUT4 expression in proliferative explants treated with estrogen and progesterone, as well as

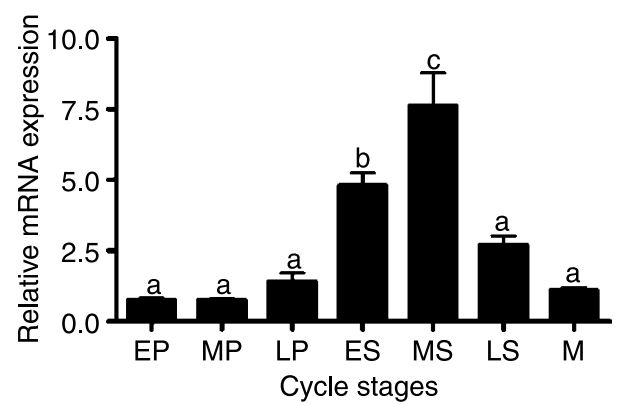

Figure 1 Relative FUT4 mRNA expression levels by real-time RT-PCR during the menstrual cycle. Mean mRNA levels in arbitrary units are shown on the $y$-axis, with results corrected against expression of $18 \mathrm{~S}$ rRNA. Error bars represent 1 S.E.M. Groups that do not share a letter in common are significantly different by parametric one-way ANOVA, with Bonferroni correction. Cycle stages are shown on the $x$-axis. EP, early proliferative; MP, mid-proliferative; LP, late proliferative; ES, early secretory; MS, mid-secretory; LS, late secretory; and $M$, menstrual. Total number of samples used is 64 . secretory explants treated with progesterone alone, or estrogen and progesterone, these did not reach significance (Fig $3 \mathrm{~A}$ and $\mathrm{B}$ ). This may be due to low sample numbers. After $48 \mathrm{~h}$, the increase was lost in both proliferative and secretory endometrial explants treated with progesterone (Fig. 3C and D). FUT4 mRNA levels did not change significantly in explants of proliferative or secretory endometria that were treated with estrogen alone for 24 or $48 \mathrm{~h}$ (Fig. 3).

\section{Steroid hormone regulation of FUT4 protein expression after $24 h$}

The effects of steroid hormones on FUT4 translation were examined by Western blotting in proliferative endometria after $24 \mathrm{~h}$ of hormonal treatments. FUT4 protein expression was significantly stronger $(P \leq 0.05)$ in explants treated with progesterone alone, compared with the control (Fig. 4). There were no significant differences in FUT4 protein expression between other groups.

\section{Discussion}

This study demonstrates the cyclic changes and hormonal regulation of FUT4 mRNA and the localization of FUT4 protein in human endometrium. Our data show that FUT4 mRNA is significantly upregulated during the early and mid-secretory phases compared with other phases of the menstrual cycle, and that FUT4 mRNA and protein expression is induced in progesterone-treated in vitro explants after $24 \mathrm{~h}$ in culture. The protein is localized to glandular and luminal epithelia.

The FUT4 gene family encodes enzymes that transfer fucose in $\alpha 1,3$ linkage on a variety of glycans. Fucosylated glycans linked to proteins are involved in many biological processes such as cell adhesion during development, inflammatory response, leukocyte trafficking, and fertilization (Javaud et al. 2003). It is likely that FUT4 regulates the expression of carbohydrate antigens that facilitate the initial attachment of blastocyst to endometrial epithelium.

Leukocyte rolling is a crucial step in leukocyte adhesion to the endothelium before moving through the endothelial layer into the tissue. Leukocyte rolling is mediated by a class of adhesion molecules known as selectins (Lasky 1992), which bind to sialylated and fucosylated oligosaccharide antigens such as $\operatorname{Le}^{\mathrm{x}}$ and $\mathrm{sLe}^{\mathrm{x}}$. Regulated specific expression of the $\alpha 1,3$ fucosyltransferases responsible for fucosylation controls the expression of these antigens (Burne \& Rabb 2002). Leukocyte homing was eliminated in mice that lack both FUT4 and FUT7 (Homeister et al. 2001). In addition, data from Weninger et al. (2000) showed that FUT4 is crucial for the selectinmediated slow rolling of leukocytes on endothelial cells. FUT4 was the first leukocyte-associated enzyme linked to selectin ligand synthesis (Goelz et al. 1990, 1994, Burne \& Rabb 2002), such as Lex, Le $^{y}$, and sLe ${ }^{x}$, although the activity for sLe ${ }^{\mathrm{x}}$ synthesis is very weak. 

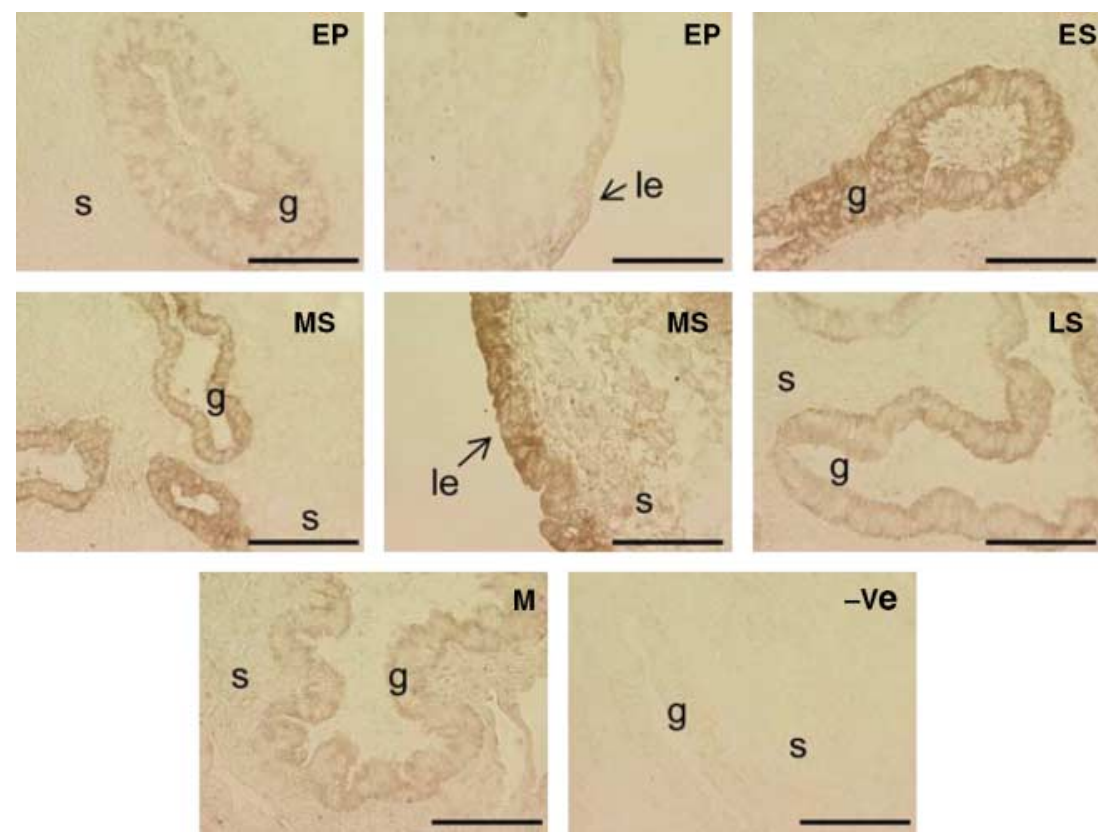

\section{ES}

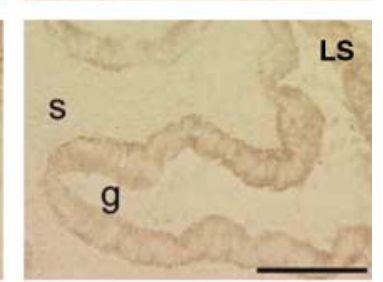

Ve

Figure 2 Representative micrographs of immunolocalization of FUT4 protein in human endometrium during the menstrual cycle. FUT4 protein was localized to glandular and the luminal epithelia of the endometrium. EP, early proliferative; ES, early secretory; MS, mid-secretory; LS, late secretory; M, menstrual; g, glandular epithelium; s, stroma; le, luminal epithelium; and -ve, negative control (goat IgG). Scale bar is $50 \mu \mathrm{m}$.
The similarities between leukocyte rolling on endothelial cells and the initial stages of blastocyst attachment to the endometrial epithelium in humans have been recognized in recent years (Genbacev et al. 2003, Dominguez et al. 2005). The L-selectin system has also been shown to be important in the initial contact of the trophoblast to the luminal epithelium of human endometrium. The human trophoblast expresses high levels of L-selectin after hatching and uses L-selectin to bind to uterine epithelial oligosaccharide ligands. When L-selectin is blocked by specific antibodies, human trophoblast adhesion to the epithelium is impaired in vitro (Genbacev et al. 2003). In the endometrial epithelium, the levels of glycosylation increase significantly during the implantation period under the influence of progesterone (Aplin et al. 1997), which gives rise to changes in the glycoprotein composition of the cell surface and secretions. Changes include the upregulation of oligosaccharide ligands that bind to L-selectin in the endometrial epithelium during the time of implantation. Studies show that $s \mathrm{Se}^{\mathrm{x}}$ is expressed in human endometrium throughout the menstrual cycle with a significant increase from early to mid-secretory phases (Ravn et al. 1992, Hey \& Aplin 1996). Lai et al. (2005) showed that the expression of L-selectin ligands that bind to MECA-79 antibody (an antibody that recognizes a sulfate and carbohydrate epitope on a group of endothelial L-selectin ligands) significantly increases throughout the early and mid-secretory stages of the menstrual cycle. Therefore, it is possible that FUT4 participates in the production of these ligands. Interestingly, L-selectin-deficient mice are fertile. There are considerable differences in the processes of implantation between mice and humans, thus whether other selectins or integrin ligands compensate for this deficiency, or the role of L-selectin in implantation is restricted to humans, remain to be elucidated.

The $\operatorname{Le}^{y}$ is another carbohydrate antigen that may facilitate the initial attachment of the trophoblast to the endometrium. It is present on the blastocyst surface (Fenderson et al. 1986, Kimber 1990) as well as on the luminal epithelium of the mouse endometrium (Kimber et al. 1988, Kimber \& Lindenberg 1990, Zhu et al. 1995).
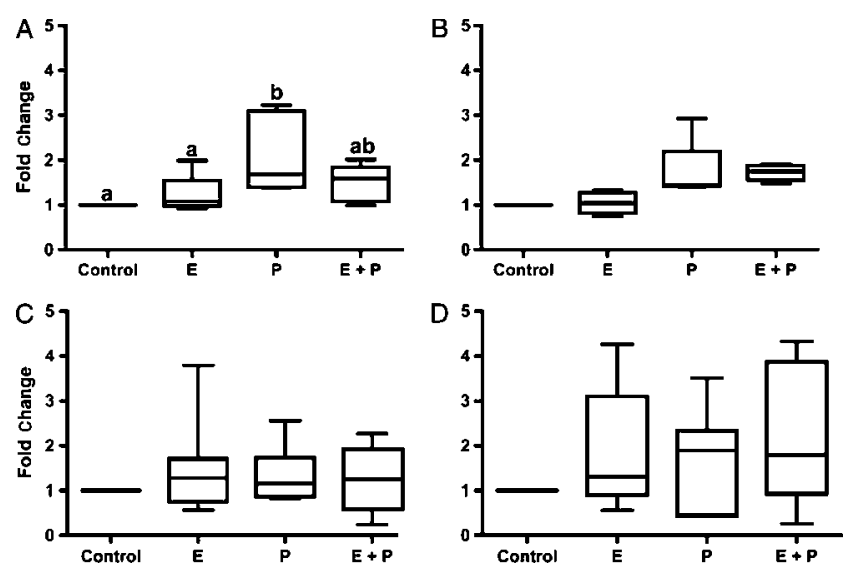

Figure 3 Effects of ovarian steroids on FUT4 mRNA in endometrial explant culture (A) after $24 \mathrm{~h}$ from proliferative phase samples $(n=8)$ and (B) secretory phase samples $(n=4)$, and (C) $48 \mathrm{~h}$ for proliferative phase samples $(n=8)$ and (D) secretory phase samples $(n=8)$. The $y$-axis shows the fold change of mRNA levels following different treatments compared with control, with all results corrected against expression of $18 \mathrm{~S}$ rRNA. The $x$-axis shows the different treatment groups: C, control; $\mathrm{E}, 10 \mathrm{nM}$ estrogen; $P, 100 \mathrm{nM}$ progesterone; and $\mathrm{E}+\mathrm{P}$, both $10 \mathrm{nM}$ estrogen and $100 \mathrm{nM}$ progesterone. Groups that do not share a letter in common are significantly different $(P<0.05)$. 

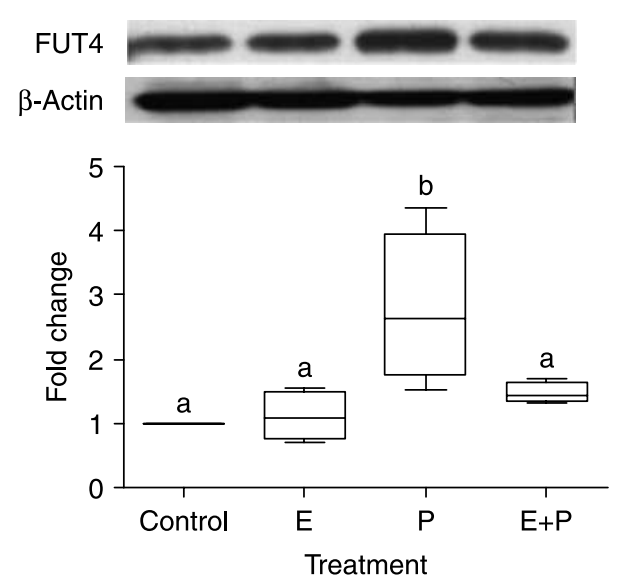

Figure 4 Quantitative analysis of the effects of ovarian steroids on FUT4 protein in endometrial explant culture after $24 \mathrm{~h}(n=4)$. Data are shown for proliferative phase endometrial explants. Representative SDS-PAGE for FUT4 band is shown above each graph. The $y$-axis shows the fold change of protein levels following different treatments compared with control, with all results corrected against expression of $\beta$-actin, and the $x$-axis shows the different treatment groups: C, control; $\mathrm{E}, 10 \mathrm{nM}$ estrogen; $P, 100 \mathrm{nM}$ progesterone; and $E+P$, both $10 \mathrm{nM}$ estrogen and $100 \mathrm{nM}$ progesterone. Groups that do not share a letter in common are significantly different $(P<0.05)$. $\beta$-Actin staining is shown as the loading control.

Injection of $\mathrm{mAb}$ to $\mathrm{Le}^{\mathrm{y}}$ into the murine uterus on day 4 of pregnancy inhibits blastocyst implantation (Zhu et al. 1995). The expression of $\mathrm{Le}^{y}$ has been shown to be significantly upregulated during the early and midsecretory phases of the menstrual cycle in humans (Ravn et al. 1992). Furthermore, Ghosh et al. (1998) reported that $\mathrm{Le}^{\mathrm{y}}$ expression peaks during the midsecretory period in rhesus monkeys. It was also shown that treatment with a low dose of the anti-progestin mifepristone significantly inhibited the expression of $\mathrm{Le}^{\mathrm{y}}$, suggesting that it is regulated by progesterone in rhesus monkeys. Since the final step in the production of $\mathrm{Le}^{\mathrm{y}}$ is catalyzed by FUT4, it is likely that progesterone effects the expression of Le ${ }^{y}$ through its regulation of FUT4.

Apart from the glycans discussed above, several other hormonally modulated glycans are also upregulated during the time of implantation in endometrial epithelium. Hence, there is also a possibility that FUT4 might play a part in the regulation and maintenance of glycocalyx in the endometrium during implantation.

To our knowledge, this is the first study to report hormonal regulation of a member of the subfamily $\alpha 1,3$ fucosyltransferases. However, there are studies reporting the hormonal regulation of $\alpha 1,2$ fucosyltransferases. Data from Sidhu \& Kimber (1999) showed that the expression of FUT1, a member of $\alpha 1,2$ fucosyltransferase family, is significantly upregulated around day 1 of pregnancy in mice and that estrogen treatment increases the expression of FUT1 in ovariectomized mice. FUT1 catalyzes the final step in the production of H-type- 1 antigen. Evidence from mouse studies suggests that $\mathrm{H}$-type- 1 antigens may also be involved in the initial adhesion cascade of trophoblast to the luminal epithelium of the endometrium (Kimber et al. 1993). No studies have been performed to examine the cyclic changes in humans. Interestingly, H-type- 1 antigen expression appears to be stimulated by estrogen in mice but progesterone in rats (Kimber et al. 1995, Sidhu \& Kimber 1999), which suggests that there may be species differences in the regulation of these enzymes. DNA and protein sequence analysis of $\alpha 1,2$ fucosyltransferases from different species including humans showed that they contain hormone responsive elements with well-conserved nucleotide sequences within the promoter regions, giving direct hormonal responsiveness via nuclear steroid receptors (Medvedova et al. 2003). However, this study did not specify which steroid hormone-response elements were present, nor did they find any hormone-response elements for $\alpha 1,3$ fucosyltransferases.

In conclusion, this study has shown that the expression of FUT4, an enzyme responsible for the final catalyzing step in the production of many L-selectin ligands is upregulated in human endometrium during the period of implantation and is regulated by progesterone.

\section{Materials and Methods}

\section{Tissue collection}

Ethical approval for the study was obtained from Southern Health Human Research and Ethics Committee B. Endometrial biopsies were obtained from normal cycling women after informed consent. All endometrial samples used in the study were classified as normal by routine histopathology. Subjects ranged in age between 18 and 47 years and had not used hormonal contraception in the 3 months prior to tissue collection. A small portion of the tissue was sent to histopathology to evaluate the cycle stage. An experienced pathologist later reconfirmed the cycle stage of each tissue sample. For the evaluation of mRNA and protein profiles, the menstrual cycle stages of 64 samples were divided into seven groups by histopathology, based on well-established criteria (Noyes et al. 1950): early proliferative (EP, $n=8$ ), midproliferative (MP, $n=11)$, late proliferative $(\mathrm{LP}, n=6)$, early secretory ( $E S, n=10)$, mid-secretory (MS, $n=11$ ), late secretory (LS, $n=10)$, and menstrual $(M, n=8)$. Endometrial tissues were either snap-frozen on dry ice immediately after collection and stored at $-80^{\circ} \mathrm{C}$ until RNA and protein extraction, or frozen in OCT for immunohistochemistry. All the immunohistochemistry work was performed on hysterectomy specimens. The RNA and protein work were performed on either curettes or hysterectomies.

The methods for the endometrial explant system were performed as described in Ponnampalam \& Rogers (2006) with slight modifications. Endometrial biopsies were collected in ice-cold phenol red-free HEPES-buffered Dulbecco's modified Eagle's medium/Hams F-12 (DMEM/F-12; Invitrogen) with $1 \%$ antibiotic-antimycotic solution (final concentrations: $100 \mu \mathrm{g} / \mathrm{ml}$ penicillin $\mathrm{G}$ sodium, $100 \mu \mathrm{g} / \mathrm{ml}$ streptomycin sulfate, and $0.25 \mu \mathrm{g} / \mathrm{ml}$ amphotericin B; Invitrogen). A small portion of the tissue was sent to histopathology to evaluate the 
cycle stage, which was recorded as either proliferative or secretory. Endometrial samples were cut into pieces of about $1 \mathrm{~mm}^{3}$ with a sterile surgical blade and placed in tissue culture inserts ( 6 explants/12 mm insert; Millipore, North Ryde, NSW, Australia). DMEM, free of serum and phenol red (supplemented with $1 \%$ antibiotic-antimycotic solution), was placed in the lower chamber (300 $\mu \mathrm{l}$ in $12 \mathrm{~mm}$ inserts). Medium was either hormone free, or supplemented with $10 \mathrm{nM}$ estrogen $(E)$, $100 \mathrm{nM}$ progesterone $(\mathrm{P})$, or a combination of both $(\mathrm{E}+\mathrm{P})$. At the end of the culture (after 24 or $48 \mathrm{~h}$ ), explants were stored at $-80{ }^{\circ} \mathrm{C}$ until RNA and protein extraction.

\section{RNA extraction and RT}

Total RNA was extracted using Trizol reagent (Invitrogen Life Technologies). Curettings were homogenized (800 $\mu$ l Trizol $+200 \mu \mathrm{g}$ glycogen) and incubated at room temperature for $5 \mathrm{~min}$. After the addition of chloroform $(0.2 \times$ volume of Trizol), the samples were incubated for another $3 \mathrm{~min}$ at room temperature, centrifuged for $15 \mathrm{~min}$ at $12000 \mathrm{~g}\left(4^{\circ} \mathrm{C}\right)$, the aqueous phase RNA was separated from DNA/protein fraction, mixed with $400 \mathrm{ml}$ isopropanol, and incubated at room temperature for $20 \mathrm{~min}$. This was followed by centrifugation for $10 \mathrm{~min}$ at $12000 \mathrm{~g}\left(4{ }^{\circ} \mathrm{C}\right)$. The RNA pellet was washed twice with $75 \%$ ethanol followed by centrifugation for $6 \mathrm{~min}$ at $10000 \mathbf{g}\left(4^{\circ} \mathrm{C}\right)$. RNA was resuspended in RNase-free water. To eliminate potential genomic DNA contamination, RNA samples were treated with RNase-free DNase (Promega) according to the manufacturer's instructions. After the DNase treatment, RNA was purified by storing overnight at $-20{ }^{\circ} \mathrm{C}$ in two volumes of $100 \%$ ethanol and 0.1 volume of $3 \mathrm{M}$ sodium acetate. RNA was centrifuged at $12000 \mathrm{~g}$ for $40 \mathrm{~min}$ at $4{ }^{\circ} \mathrm{C}$, the pellet was washed twice with $70 \%$ ethanol, and then the RNA was resuspended in RNase-free water. Quantification and estimation of purity were derived by measuring the absorbance of each RNA sample at 260 and $280 \mathrm{~nm}$. The cutoff 260/280 ratio for the sample inclusion was 1.8-2.1. All RNA samples were stored at $-80^{\circ} \mathrm{C}$ until use. RT was performed using Superscript III Reverse Transcriptase (Invitrogen) according to the manufacturer's instructions. RNA $(0.5 \mu \mathrm{g})$ from each sample was used.

\section{Real-time quantitative RT-PCR (RT-QPCR)}

A Roche Light Cycler and an LC Fast Start DNA Master SYBR Green Kit were used to perform the real-time PCR according to the manufacturer's instructions. Primer concentrations were $0.5 \mu \mathrm{mol} / \mathrm{l}$. Each set of primers was optimized for annealing temperature and extension times. The primer sequences used and the protocols are shown in Table 1. Relative mRNA expression was determined by the measurement against a specific cDNA standard. 18S rRNA was used as a housekeeping gene to normalize all results.

\section{Immunohistochemistry}

Frozen full-thickness endometrial tissue samples were cut into $5 \mu \mathrm{m}$ sections and fixed in cold acetone for $10 \mathrm{~min}$. Endogenous peroxidase activity was blocked prior to immunohistochemistry by incubation in $0.3 \% \mathrm{H}_{2} \mathrm{O}_{2}$ in methanol for 10 min. Tissue sections were then washed in PBS and blocked with protein blocking solution for $30 \mathrm{~min}$ (PBA; Immunon Shandon, Pittsburgh, PA, USA) to prevent non-specific binding, followed by overnight incubation at $4{ }^{\circ} \mathrm{C}$ with goat anti-human FUT4 antibody $(1.3 \mu \mathrm{g} / \mathrm{ml}$ sc-20477 in 1\% BSA in PBS; Santa Cruz Biotechnology, Santa Cruz, CA, USA). Negative control was goat $\operatorname{lgG}$ at $1.3 \mu \mathrm{g} / \mathrm{ml}$. The primary antibody step was followed by a biotinylated secondary antibody and streptavidin-peroxidase steps at room temperature for $15 \mathrm{~min}$ each, using reagents of the LSAB + Kit (Dako, Carpinteria, CA, USA). $\mathrm{DAB}$ (Sigma) was applied for $5 \mathrm{~min}$ at room temperature as a chromogen.

\section{Protein extraction}

Total protein was extracted from endometrial tissues/explants using Trizol reagent according to the manufacturer's instructions. Following RNA/DNA removal, the protein pellet was washed and dissolved in $1 \%$ SDS. Protein quantification was performed by BCA Protein Assay Kit, following manufacturer's instructions (Pierce Biotech, Rockford, IL, USA).

\section{Western blotting}

Twenty micrograms of protein from total endometrial tissues were subjected to SDS-PAGE. The protein samples were mixed with $2 \times$ SDS loading buffer with or without 2-mercapto ethanol, and the samples were heated at $95{ }^{\circ} \mathrm{C}$ for $5 \mathrm{~min}$ (for reducing conditions) or warmed at $40{ }^{\circ} \mathrm{C}$ for $15 \mathrm{~min}$ (for non-reducing conditions). The SDS-PAGE was run on a $10 \%$ agarose gel at $100 \mathrm{~V}$ for $1 \mathrm{~h}$. The proteins resolved in the gel were electrophoretically transferred overnight to nitrocellulose membrane (Bio-Rad). The transferred membrane was treated with blocking solution for $1 \mathrm{~h}$ (SuperBlock; Pierce Biotech). The membrane was then incubated with 1:1000 dilution of the goat anti-human FUT4 antibody (sc-20477; Santa Cruz Biotechnology) for $1 \mathrm{~h}$. This was followed by washing and incubation with horse-radish

Table 1 Primer sequences, Light Cycler conditions used, and amplicon sizes for fucosyltransferase 4 (FUT4) and 18S rRNA.

\begin{tabular}{|c|c|c|c|c|c|}
\hline Gene & Primer sequence & $\begin{array}{c}\text { Annealing } \\
\text { temperature } \\
\left({ }^{\circ} \mathrm{C}\right)\end{array}$ & $\begin{array}{l}\text { Extension } \\
\text { time }(\mathrm{s})\end{array}$ & $\begin{array}{l}\text { Amplicon } \\
\text { size (bp) }\end{array}$ & Reference \\
\hline FUT4 & $\begin{array}{l}\text { Sense: } 5^{\prime} \text {-CAG CTG GTT CGA GCG GTG AAG CCG CGC T-3' } \\
\text { Antisense: } 5^{\prime} \text {-CAG AAA AAC GTG AAT CGG GAA CAG TTG TGT-3' }\end{array}$ & 63 & 16 & 435 & $\begin{array}{l}\text { Taniguchi } \\
\text { et al. (2000) }\end{array}$ \\
\hline $18 \mathrm{~S}$ rRNA & $\begin{array}{l}\text { Sense: 5'-CGG CTA CCA CAT CCA AGG AA-3' } \\
\text { Antisense: } 5^{\prime} \text {-GCT GGA ATT ACC GCG GCT-3' }\end{array}$ & 60 & 10 & 187 & $\begin{array}{l}\text { Ponnampalam } \\
\text { et al. } 2004\end{array}$ \\
\hline
\end{tabular}


peroxidase (HRP)-conjugated rabbit anti-goat secondary antibody (1:50 000; Zymed Laboratories, South San Francisco, CA, USA) and finally developed using Supersignal West Dura Extended Duration Substrate (Pierce Biotech) according to the manufacturer's instructions. The developed films were scanned and assessed by densitometry (Quantity One Software, Bio-Rad). Pre-stained SDS-PAGE standard protein markers (Bio-Rad) were used to calibrate the molecular mass. $\beta$-Actin was used as the loading control (1:4000 dilution; Sigma-Aldrich).

\section{Statistical analysis}

Statistical tests were performed using the SPSS 12 statistical analysis package (SPSS Inc., Chicago, IL, USA) and GraphPad Prism software (version 4.00; GraphPad Software, San Diego, CA, USA). For mRNA profile of FUT4 during the menstrual cycle, one-way ANOVA with Bonferroni correction was used. For hormonal regulation data, the fold change of the hormonal treated samples over the controls within each experiment was calculated. The effect of treatments on fold change in mRNA expression was analyzed using Friedman test with Dunn correction. $P \leq 0.05$ was considered significant.

\section{Acknowledgements}

We thank Leonie Cann for her technical assistance with immunohistochemistry. We also thank Sisters Nancy Taylor and Nicki Sam for the collection of tissue samples and to various gynecological surgeons affiliated with Monash Medical Centre who provided subjects for the study. We are grateful to Dr Beatrice Susil for histopathological evaluation of all the endometrial tissue samples. P A W R's salary was provided by NH \& MRC Fellowship Grant No. 143805. The authors declare that there is no conflict of interest that would prejudice the impartiality of this scientific work.

\section{References}

Aplin JD, Jones CJ, McGinlay PB, Croxatto HB \& Fazleabas AT 1997 Progesterone regulates glycosylation in endometrium. Biochemical Society Transactions 25 1184-1187.

Blander JM, Visintin I, Janeway CA Jr \& Medzhitov R 1999 Alpha(1,3)fucosyltransferase VII and alpha(2,3)-sialyltransferase IV are up-regulated in activated CD4 T cells and maintained after their differentiation into Th1 and migration into inflammatory sites. Journal of Immunology $\mathbf{1 6 3}$ $3746-3752$.

Burne MJ \& Rabb H 2002 Pathophysiological contributions of fucosyltransferases in renal ischemia reperfusion injury. Journal of Immunology $1692648-2652$.

Clarke JL \& Watkins W 1996 Alpha1,3-L-fucosyltransferase expression in developing human myeloid cells. Antigenic, enzymatic, and mRNA analyses. Journal of Biological Chemistry 271 10317-10328.

Dominguez F, Yanez-Mo M, Sanchez-Madrid F \& Simon C 2005 Embryonic implantation and leukocyte transendothelial migration: different processes with similar players? FASEB Journal 19 1056-1060.

Fenderson BA, Holmes EH, Fukushi Y \& Hakomori S 1986 Coordinate expression of $\mathrm{X}$ and $\mathrm{Y}$ haptens during murine embryogenesis. Developmental Biology 114 12-21.

Genbacev OD, Prakobphol A, Foulk RA, Krtolica AR, Ilic D, Singer MS, Yang ZQ, Kiessling LL, Rosen SD \& Fisher SJ 2003 Trophoblast L-selectinmediated adhesion at the maternal-fetal interface. Science 299 405-408.

Ghosh D, Liu N, Zhu ZM \& Sengupta J 1998 Immunolocalization of Le(y) oligosaccharide in endometrium during menstrual cycle and effect of early luteal phase mifepristone administration on its expression in implantation stage endometrium of the rhesus monkey. Human Reproduction 13 1374-1379.

Goelz SE, Hession C, Goff D, Griffiths B, Tizard R, Newman B, Chi-Rosso G \& Lobb R 1990 ELFT: a gene that directs the expression of an ELAM-1 ligand. Cell 63 1349-1356.

Goelz S, Kumar R, Potvin B, Sundaram S, Brickelmaier M \& Stanley P 1994 Differential expression of an E-selectin ligand (SLex) by two Chinese hamster ovary cell lines transfected with the same alpha $(1,3)$-fucosyltransferase gene (ELFT). Journal of Biological Chemistry 269 1033-1040.

Hey NA \& Aplin JD 1996 Sialyl-Lewis $x$ and Sialyl-Lewis a are associated with MUC1 in human endometrium. Glycoconjugate Journal 13 769-779.

Homeister JW, Thall AD, Petryniak B, Maly P, Rogers CE, Smith PL, Kelly RJ, Gersten KM, Askari SW, Cheng G et al. 2001 The alpha(1,3)fucosyltransferases FucT-IV and FucT-VII exert collaborative control over selectin-dependent leukocyte recruitment and lymphocyte homing. Immunity 15 115-126.

Huang MC, Zollner O, Moll T, Maly P, Thall AD, Lowe JB \& Vestweber D 2000 P-selectin glycoprotein ligand-1 and E-selectin ligand-1 are differentially modified by fucosyltransferases Fuc-TIV and Fuc-TVII in mouse neutrophils. Journal of Biological Chemistry 275 31353-31360.

Javaud C, Dupuy F, Maftah A, Julien R \& Petit JM 2003 The fucosyltransferase gene family: an amazing summary of the underlying mechanisms of gene evolution. Genetica 118 157-170.

Kimber SJ 1990 Glycoconjugates and cell surface interactions in pre- and peri-implantation mammalian embryonic development. International Review of Cytology 120 53-167.

Kimber SJ \& Lindenberg S 1990 Hormonal control of a carbohydrate epitope involved in implantation in mice. Journal of Reproduction and Fertility 89 13-21.

Kimber SJ, Lindenberg S \& Lundblad A 1988 Distribution of some Gal beta 1-3(4)GlcNAc related carbohydrate antigens on the mouse uterine epithelium in relation to the peri-implantational period. Journal of Reproductive Immunology 12 297-313.

Kimber SJ, Brown DG, Pahlsson P \& Nilsson B 1993 Carbohydrate antigen expression in murine embryonic stem cells and embryos. II. Sialylated antigens and glycolipid analysis. Histochemical Journal 25 628-641.

Kimber SJ, Illingworth IM \& Glasser SR 1995 Expression of carbohydrate antigens in the rat uterus during early pregnancy and after ovariectomy and steroid replacement. Journal of Reproduction and Fertility 103 75-87.

Lai TH, Shih le M, Vlahos N, Ho CL, Wallach E \& Zhao Y 2005 Differential expression of L-selectin ligand in the endometrium during the menstrual cycle. Fertility and Sterility 83 1297-1302.

Lasky LA 1992 Selectins: interpreters of cell-specific carbohydrate information during inflammation. Science 258 964-969.

Lowe JB 1997 Selectin ligands, leukocyte trafficking, and fucosyltransferase genes. Kidney International 51 1418-1426.

Medvedova L, Knopp J \& Farkas R 2003 Steroid regulation of terminal protein glycosyltransferase genes: molecular and functional homologies within sialyltransferase and fucosyltransferase families. Endocrine Regulations 37 203-210.

Mollicone R, Cailleau A \& Oriol R 1995 Molecular genetics of H, Se, Lewis and other fucosyltransferase genes. Transfusion Clinique et Biologique $\mathbf{2}$ 235-242.

Noyes RW, Hertig AW \& Rock J 1950 Dating the endometrial biopsy. Fertility and Sterility 1 3-25.

Ponnampalam AP \& Rogers PA 2006 Cyclic changes and hormonal regulation of annexin IV mRNA and protein in human endometrium. Molecular Human Reproduction 12 661-669.

Ponnampalam AP, Weston GC, Trajstman AC, Susil B \& Rogers PA 2004 Molecular classification of human endometrial cycle stages by transcriptional profiling. Molecular Human Reproduction 10 879-893.

Ravn V, Teglbjaerg CS, Mandel U \& Dabelsteen E 1992 The distribution of type-2 chain histo-blood group antigens in normal cycling human endometrium. Cell and Tissue Research 270 425-433.

Sidhu SS \& Kimber SJ 1999 Hormonal control of H-type alpha(12)fucosyltransferase messenger ribonucleic acid in the mouse uterus. Biology of Reproduction 60 147-157.

Taniguchi A, Suga R \& Matsumoto K 2000 Expression and transcriptional regulation of the human $\alpha 1,3$-fucosyltransferase 4 (FUT4) gene in myeloid and colon adenocarcinoma cell lines. Biochemical and Biophysical Research Communications 273 370-376. 
de Vries T, Knegtel RM, Holmes EH \& Macher BA 2001 Fucosyltransferases: structure/function studies. Glycobiology 11 119R-128R.

Wagers AJ \& Kansas GS 2000 Potent induction of alpha(1,3)-fucosyltransferase VII in activated CD4 + T cells by TGF-beta 1 through a 38 mitogen-activated protein kinase-dependent pathway. Journal of Immunology 165 5011-5016.

Weninger W, Ulfman LH, Cheng G, Souchkova N, Quackenbush EJ, Lowe JB \& von Andrian UH 2000 Specialized contributions by alpha(1,3)-fucosyltransferase-IV and FucT-VII during leukocyte rolling in dermal microvessels. Immunity 12 665-676.

Wiederschain GY, Koul O, Aucoin JM, Smith FI \& McCluer RH 1998 alpha1,3 Fucosyltransferase, alpha-L-fucosidase, alpha-D-galactosidase, beta-D-galactosidase, and Le(x) glycoconjugates in developing rat brain. Glycoconjugate Journal 15 379-388.
Withers DA \& Hakomori SI 2000 Human alpha (1,3)-fucosyltransferase IV (FUTIV) gene expression is regulated by elk-1 in the U937 cell line. Journal of Biological Chemistry 275 40588-40593.

Zhu LJ, Bagchi MK \& Bagchi IC 1995 Ferritin heavy chain is a progesteroneinducible marker in the uterus during pregnancy. Endocrinology $\mathbf{1 3 6}$ 4106-4115.

Received 9 December 2007

First decision 14 February 2008

Revised manuscript received 26 February 2008

Accepted 19 March 2008 